\title{
Teaching Assistant Competencies in Canada: Building a Framework for Practice Together
}

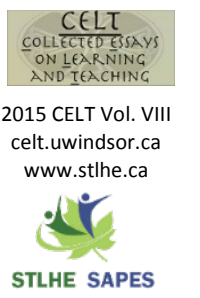

Cynthia Korpan

University of Victoria

Suzanne Le-May Sheffield

Dalhousie University

Roselynn Verwoord

University of British Columbia

This paper examines the stages of development for a framework of teaching assistant (TA) competencies initiated by the Teaching Assistant and Graduate Student Advancement (TAGSA) special interest group (SIG) of the Society of Teaching and Learning in Higher Education (STLHE). TAGSA initiated an iterative consultative process to inform the creation of the competencies that sought input from the STLHE community on four occasions. At each stage of the consultations, the competencies were formed and re-formed, their purpose and value debated, and the challenges of creating a development framework recognized. This process, described in this paper, resulted in a clear, succinct and flexible framework that can be used across institutions in multiple contexts.

\section{Introduction}

his paper examines the stages of development for
a framework of teaching assistant (TA) competencies initiated by the Teaching Assistant and Graduate Student Advancement (TAGSA) special interest group (SIG) of the Society of Teaching and Learning in Higher Education (STLHE). STLHE's mandate is to enhance teaching and learning in higher education. Similarly, TAGSA seeks to raise the profile of TA and graduate student development in Canada by providing leadership and undertaking initiatives to support the attainment of teaching and professional skills through a strong network of likeminded professionals and students.

TAGSA began working on this framework in the fall of 2012 to support institutions, departments, schools, faculty, educational developers, TAs, and others responsible or interested in the teaching preparation of TAs. The framework took as its starting point and inspiration, STLHE's Ethical Principles in University Teaching, developed in 1996 by $3 \mathrm{M}$ National Teaching Fellows, faculty members from post-secondary institutions across Canada who have received a $3 \mathrm{M}$ National Teaching Fellowship, the most prestigious teaching award in Canada. 
The development of the framework is timely. As competition for jobs increases, universities in Canada are attracting increasing numbers of Master's and Doctoral students (Association of Universities and Colleges of Canada [AUCC], 2011; Maldonado, Wiggers, \& Arnold, 2013; Rose, 2012). In addition to undertaking advanced studies, many of these students take on important teaching roles at the undergraduate level as tutors, markers, tutorial leaders, lab or discussion leaders, and TAs. Many of these students seek training through formal TA programs as well as through workshops and seminars, in order to prepare for their various teaching roles (McAlpine \& Åkerlind, 2010). These programs are often offered through learning and teaching centres, but the content, quality, and outcomes of these programs vary greatly (Roehrig, Luft, Kurdziel, \& Turner, 2003), leading to inconsistency in the kinds of skills and abilities that TAs develop.

The introduction of the framework for TA competencies - statements that define what being a capable TA looks like - is one way that universities can begin to articulate a common knowledge and skill set for TA work. TA competencies can give ownership of the learning process to TAs by identifying expected areas and levels of performance, thus allowing TAs to self-assess their skills and performance. From an organizational standpoint, the adoption of TA competencies would help educational developers design more effective TA training programs that ensure that all TAs have a common learning experience. In articulating TA competencies, it is important that the competencies are strictly connected to TA skills and performance, as opposed to graduate student professional development, in general. This separation ensures that the acquisition of skills related to graduate student teaching is seen as a specific and valued task.

Once development began, TAGSA became aware of a similar effort by the Graduate Student Professional Development (GPSD) group that is part of the Professional and Organizational Development Network in Higher Education (POD) in the United States. GPSD kindly shared their draft competencies with TAGSA. A distinct difference existed between what TAGSA was envisioning compared to GPSD's competencies. GPSD's were broad in scope and focused on developing graduate students as educators and for academic careers. TAGSA's focus was strictly on TA development.

Despite the existence of literature that delves into TA and graduate student competencies (Schönwetter \& Ellis, 2007; Simpson \& Smith, 1993) and the existence of previous work on graduate student competencies (i.e. POD's graduate student development work), TAGSA believed in the importance of an iterative consultative process to inform the creation of the competencies. Such an approach is, of course, in keeping with the collaborative spirit of TAGSA, and STLHE more broadly. Moreover, TAGSA members who led this project believed that conversation with educational developers and those in the higher education community, would deepen and enrich our own discussions and would result in a more comprehensive set of competencies. In addition, our hope was that seeking input from others would result in stronger interest in, commitment to, and use of the competencies when they were completed.

As a result, TAGSA sought input from the STLHE community on four occasions, in addition to an informal TA focus group. Beginning with the educational development community, Cynthia Korpan, Suzanne Le-May Sheffield and Svitlana Taraban-Gordon, three TAGSA executive committee members, held a pre-conference session at the 2013 Educational Developer's Caucus (EDC) conference in Waterloo, Ontario, presenting a possible competency framework and seeking feedback. Building on the work in the first session, the second session led by TAGSA executive committee members Cynthia Korpan, Suzanne Le-May Sheffield, and Roselynn Verwoord, was an opportunity for participants to provide input at a pre-conference workshop at the 2013 STLHE Conference in Cape Breton. The third opportunity for feedback was provided at the 2014 Calgary EDC conference led by Cynthia Korpan and Suzanne Le-May Sheffield. Finally, the competencies were shared by Cynthia Korpan and Roselynn Verwoord at the 2014 inaugural TAGSA pre-conference as part of the STLHE Conference at Queen's University in 
Kingston. This iterative consultative process resulted in valuable contributions from the higher education community that substantially informed the TA competencies. At each stage of the consultations, the competencies were formed and re-formed, their purpose and value debated, and the challenges of creating a developmental framework recognized. This process, described below, resulted in a clear, succinct and flexible framework that can be used across institutions in multiple contexts.

\section{Stages of Development}

\section{Beginning the iterative process}

A discussion paper (Korpan, 2012) was distributed to participants prior to the 2013 EDC session, providing a general overview of TA responsibilities, available professional development opportunities for TAs that varies across institutions, and the need for more focused and consistent professional development of teaching for this group. The paper also outlined other already-existing frameworks that this TA Competency Framework could draw upon. These previous frameworks included STLHE's Ethical Principles in University Teaching (1996) in Canada, and Simpson and Smith's (1993) 26 competencies (grouped into six skill areas) based on US expert consensus. The purpose of sharing this paper with workshop participants was to help participants to think about the possible value of establishing TA competencies and the possible nature of these competencies.

At the outset of the session, the three facilitators presented definitions of 'competency'. The first definition of 'competency' was "combinations of those cognitive, motivational, moral and social skills available to (or potentially learnable by) a person or a social group that underlie the successful mastery through appropriate understanding and actions of a range of demands, tasks, problems and goals" (Weinert, 2001). The second definition was from Smith $(1996,2005)$ and focused on the ability to take domain knowledge and use it in new situations, demonstrating that a person is able to successfully synthesize knowledge to do a certain thing in the right context.

Within the frame of these definitions of competency, the group was asked to consider the benefits or detractions of a national set of competencies for TAs and decided that the benefits far outweighed any issues that might arise. They believed that a national framework would provide clear benchmarks that would give profile, recognition, legitimacy, and credibility to TA work. They also recognized that a national framework would allow institutions to view TAs as having established transferable competencies. This consistency would enable research to be conducted nationally in this field of study. Concern was raised, however, about a framework being used to established a 'minimum' standard that might result in 'teaching to the standard' and not beyond, or using the standard as an evaluation tool rather than as a developmental tool. These concerns were recorded by the executive in order to inform future work.

In the second part of this session, the facilitators suggested three core competency categories: cognitive (TA knowledge), functional (TA skills), and social (TA attitude, behaviour and efficacy). While these categories were open for debate, the plan for this part of the session was to focus the discussion on the skill sets that educational developers believed TAs should demonstrate within each competency category. The group of approximately 20 educational developers worked in small groups to explore each of these categories and then came together in the larger group to share the ideas generated. The value of a TA competency framework was realized through these conversations, as we explored the breadth and depth of our expectations for TAs. This was perhaps the key takeaway from the session.

The following areas of focus were suggested by the group for the cognitive category: (1) disciplinespecific knowledge, (2) pedagogical knowledge (including an awareness of the scholarship of teaching and learning), and (3) institutional knowledge. There was some debate as to whether 'approaches to learning' should be included in this category. For the 
functional (or skills) category, the group included the following areas: (1) approaches to learning, (2) navigate challenges using policies, (3) time management and priority setting, (4) classroom management, (5) fair and equitable evaluation/assessment (use of rubrics), and (6) managing students expectations. The last category, social, included: (1) relationship with course professor, (2) knowing rights and responsibilities, (3) communication, (4) reflective practice, and (5) service mission.

At the end of the session the facilitators introduced the idea of a developmental competency model. We asked the group to consider whether it would be useful to organize the competencies they had named into categories for first-time, mid-term, and experienced TAs. In principle, participants felt that a developmental model was useful and appropriate. However, this group, and subsequent groups, expressed concern that developmental levels would be difficult to standardize based on the varying backgrounds of TAs and as a result of different disciplinary and institutional contexts.

Additional issues were explored by the group as ideas unfolded including whether or not the competencies should be written in the form of learning outcomes using Bloom's Taxonomy (Bloom, 1956). There was also discussion about how the competencies would be used in practice, and thus the importance of keeping the competencies as broad categories with flexibility within each. Educational developers were certainly eager to stress the range of work, and thus the extent of the competencies, that TA appointments entail. They expressed strong opinions about the importance of recognizing TA work and supporting TA development. The group also stressed the importance of protecting TAs from premature evaluation of their work that would interfere with a professional development focus. They also remained concerned that standardization of competencies could problematize TAs learning to teach in context.

\section{Cautions, clarifications, and questions}

At the pre-conference workshop at STLHE 2013 in Cape Breton, workshop participants were first introduced to the history of TAGSA's competency development based on the work completed at EDC 2013. Most of the participants had not been involved in the previous EDC session involving the articulation of the competencies. Two goals for the session were to have participants: (1) complete the competencies for first-time TAs, with the possibility of constructing a developmental model; and (2) identify several possible competencies for TAs and how these competencies might be introduced and developed in their own contexts.

At the start of the session, the presenters provided some context for the participants by defining competencies and explaining why they were used, articulating the value of TA competencies, and identifying some of the challenges and issues. This was followed by introducing the TA development framework that incorporated feedback from the EDC conference session. The focus on the development of knowledge competencies, skills competencies, and social competencies was highlighted. In addition, the framework's inclusion of first-time TA, mid-term TA, and experienced TA competencies within each area of the framework (knowledge, skills, and social competencies), was introduced using the Dreyfus and Dreyfus (1980) model as a foundation for this developmental focus.

Finally, workshop participants were introduced to the proposed competencies (see below) for firsttime TAs. In small groups, participants were invited to refine the wording and suggest additions and deletions to the draft competencies. 


\section{Proposed First Time TA}

\section{Competencies}

\section{Knowledge competencies}

1. Preparing to be a teaching assistant. The potential TA will reflect on the values and goals associated with the discipline, and how to 'be'/'think'/'do' in the discipline. Additionally, the potential TA will reflect on what experience he or she can draw upon and apply to his or her teaching role.

2. Seeking discipline specific content knowledge: Once appointed, the TA will seek out information about content that is directly pertinent to the duties he or she is assigned. TAs will ask for the following information, if applicable, for each course: (a) how to sequence and deliver content to satisfy course goals, (b) how the course fits into the curriculum, and (c) how the discipline fits into the institutional context.

3. Inquiring about pedagogy and beginning to develop teaching identity: TAs will draw on their own experience from the discipline to inquire about the pedagogies that are favoured over others in that discipline (called signature pedagogies). TAs will also ask for other teaching methods that may be suitable for particular content (called pedagogical content knowledge). Lastly, TAs will request information regarding research about teaching and learning in the discipline (referred to as the Scholarship of Teaching and Learning (SoTL)).

4. Understanding teaching and learning: TAs will obtain information about how course objectives, activities, and assessment align in the course they are assigned. TAs will seek out knowledge about the different learning styles of students, theories that inform teaching and learning, and strategies for fair evaluation and assessment. Throughout the term, TAs will actively reflect on their teaching experience so that they may critically engage with the process to continually develop their teaching identity.

5. Awareness of institutional knowledge: TAs will be responsible for searching out the rights and responsibilities associated with their teaching role.

\section{Skill competencies}

1. Preparing to teach: TAs will seek out information about how to prepare lesson plans, rubrics, class outlines, and student feedback forms suitable for the duties assigned. Additionally, TAs will get help on how to do the following that pertain to their duties: use classroom and online technology; work with a diverse student population; give clear, concise, and stimulating presentations; keep a focus on learner centered teaching; mentor students; actively listen; give and receive feedback; help students work effectively in groups; engage in effective communication; and ask effective questions.

2. Requesting information about how to navigate challenges: TAs will ask for instruction on how to manage their time efficiently, set priorities, manage the classroom, resolve conflict, and manage student expectations.

\section{Social competencies}

1. Effective interpersonal communication: TAs will find out what questions to ask course supervisors about their TA role, while establishing and maintaining a professional relationship and interactions. With colleagues, TAs will seek out support, resources, and engage in a collegial collaborative relationship. With students, TAs will be available, approachable, inclusive, fair, and enthusiastic. 
2. Demonstrate professionalism: TAs will aim to be professional, confident, sensitive, and resilient; have integrity; maintain confidentiality of student work; balance time between work and life, and plan future goals; develop lifelong learning habits; and engage in reflective practice.

During the small group report-back, the working groups shared helpful feedback that raised larger questions about how the TA competencies would be used. For example, participants wanted to know if the competencies would be used by all TA training programs and emphasized the challenge of having first-time TA competencies for institutions where there are no TA training programs. Additionally, several participants raised questions about the appropriateness of the competencies for first-time TAs, particularly given that TAs have varied prior teaching experience and the level of complexity in the TA competencies may not be attainable for many first-time TAs. Questions were also raised about the suitability of the first-time TA competencies for the varied roles that TAs have in different institutions, particularly given that some TAs don't interact with students in their TA duties, but instead only work as marking TAs. How would the competencies reflect this variation? These cautions and questions were noted by the workshop facilitators.

Participants were then introduced to the other conceptual stages in the development model (see Figure 1) including mid-term $\mathrm{TA}$ and experienced TA, and invited to provide feedback on developing competencies using these stages.

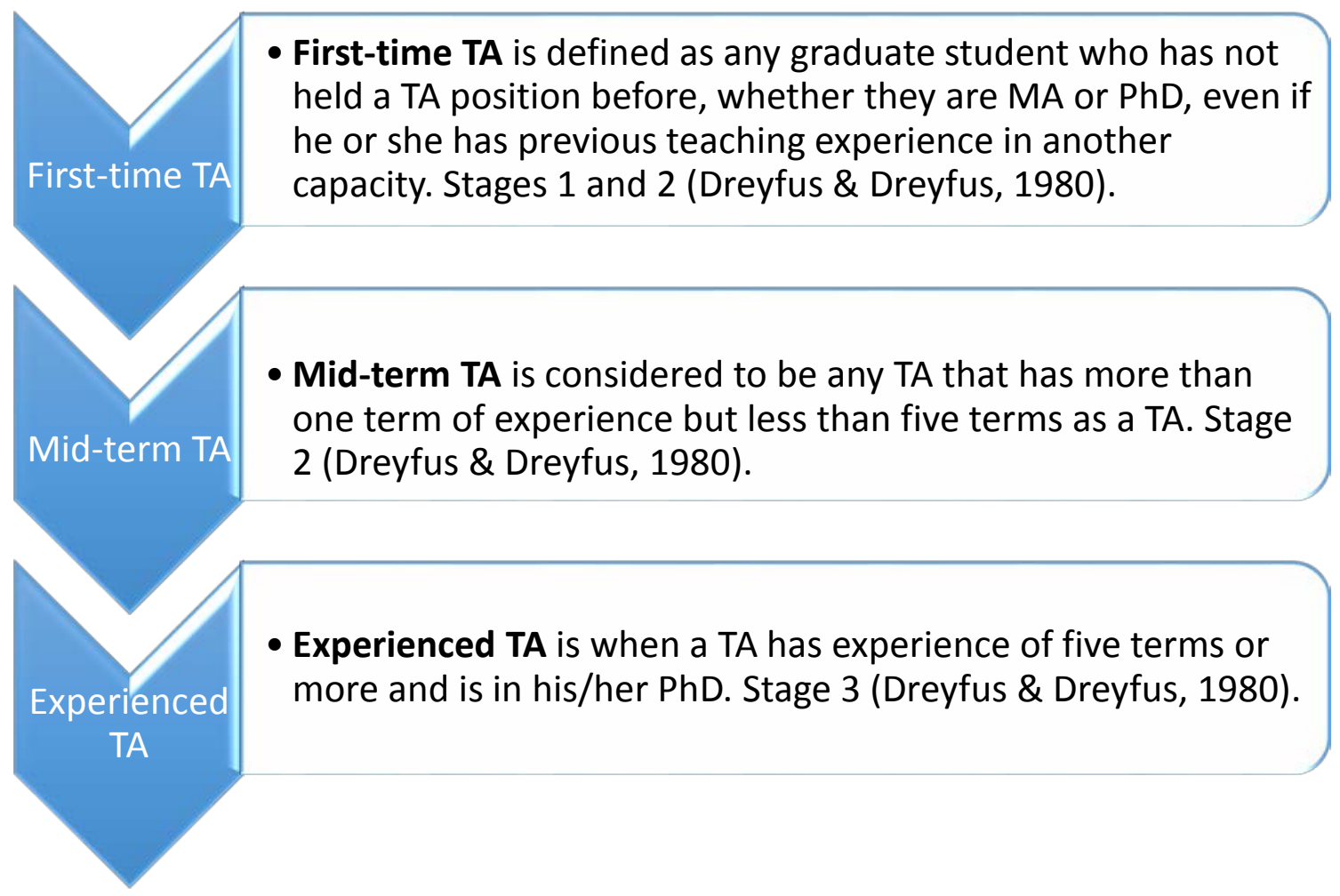

Figure 1

TA developmental competency model

During the feedback on the developmental competency model, participants raised questions about the definitions for each stage of the model including first-time TA, mid-term TA, and experienced TA, citing concerns with the varied roles that TAs may be assigned. For example, one participant mentioned that a TA could be a marker for five terms, which would place them at the mid- 
term TA level in the developmental competency model; however, they likely would not have the knowledge, skills, and social competence expected of a TA operating at this level. Additional concerns were raised about placing experienced instructors at the first-time TA level based on the fact that they haven't had any formal TA appointments but may have a wealth of experience to draw from as a previous instructor. These cautions and questions were noted.

At the culmination of the session, there seemed to be general consensus that broadening the competencies in order to increase their applicability across varied institutions and TA experiences, was the next logical step. The executive committed to working on this and to reporting back at the next EDC conference in February 2014. The revised TA competencies encouraged those working with TAs to create context-specific learning outcomes to support the attainment of the knowledge, skill, and social competencies and included examples of learning outcomes for each competency to help individuals create their own context-specific learning outcomes. The revised TA competencies also highlighted two developmental foci: before TA appointment and after TA appointment in lieu of the first-time TA, midterm TA, and experienced TA categories.

At the EDC conference in February, 2014, TAGSA ran another pre-conference workshop to refine the next version of competencies. As usual, the session provoked lively discussion. Similar issues were raised in this group (of about 12) as in the 2013 STLHE group. They noted that many variables exist within disciplines and that this fact could render the competencies not very useful. Institutions were recognized to be in constant flux and each quite different; for example, some have TA unions, or different forms and breadth of professional development. This group also wondered how to best represent and tie together the three competencies. This issue highlighted the importance of promoting the symbiotic relationships between the competencies to ensure that implementation of the competencies was mutually beneficial to all involved and that everyone in an institution who is responsible for preparing TAs has an obligation to engage with the competencies.
This group also felt strongly that the development model was not useful. Many good reasons surfaced, such as that it would be difficult to apply in all contexts because not all institutions have doctoral programs. Another issue raised was that not all competencies may be developed at the same rate, partly because of the variable TA duties and responsibilities but also because of the varied experience and educational levels of TAs. The question about competency evaluation also came up again, particularly around how to ensure that the competencies did not become a mechanism to measure minimum standards.

Going forward, despite earlier discussion about providing outcomes for each competency, the group wanted to make sure that the competencies were kept broad and not constrained by the action verbs that an outcomes approach would necessitate. It was also suggested that to encourage broad adoption and use of the competencies, development of resources for faculty and departments would be necessary. During the session, one small group of participants began to think about how they could work with such a framework to implement competencies at their institutions. The lack of outcomes did not prove to be a hindrance to this process for them.

\section{Finding Balance between Complexity and Simplicity}

Prior to the STLHE 2014 session, one of the members of the TAGSA executive invited a group of experienced TAs she works with through the Teaching Assistant Consultant (TACs) program at the University of Victoria to examine the competencies. TACs are mentors for new TAs in their respective departments and are responsible for closely assisting new TAs to ensure they have the background information, skills, and support needed as they step into the TA role. TACs viewed the competencies from their perspectives as TA mentors. The TACs suggested trimming the document. They found it overwhelming for a beginning TA and felt that 
departments and faculty would feel the same. The TACs did appreciate the inclusion of a section titled, "Before TA appointment." They felt that this set the tone for graduate students to realize the significance of the role they were taking on and to get them thinking about their upcoming TA assignment. This section was later reframed (see final version below) to acknowledge the restrictions TAs are confronted with regarding their TA appointments.

In preparation for the STLHE 2014 conference at Queen's University, the TAGSA executive committee worked towards presenting the competencies in a form that could be piloted in the upcoming academic year. We realized that we could continue to consult but that it would be difficult to reach a consensus about the content and best way to represent the competencies. This is possibly a constraint of the iterative consultative process. Therefore, taking EDC 2014 and TACs' feedback into account, we highlighted the main framework concept and created a visual representation to help tie all the competencies together. This visual representation (Figure 2) was introduced at the STLHE 2014 session. The final TA Competency Framework is depicted in Figure 3.

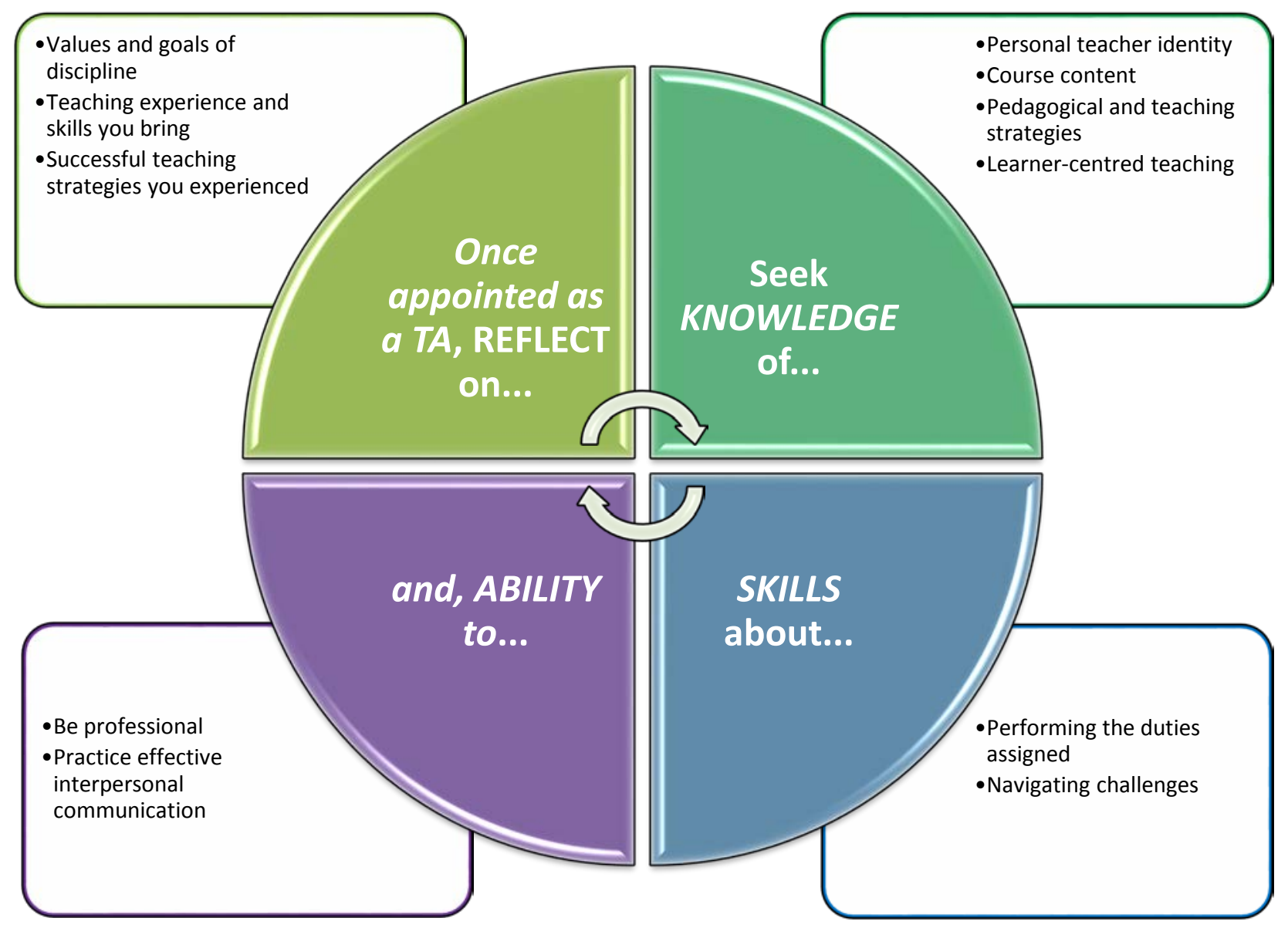

Figure 2

Framework for teaching assistant competency development 
Once appointed as a TA, REFLECT on:

1. The skills and attributes brought from previous work and disciplinary experience

Possible learning activities/goals/outcomes:

- $\quad$ Define the values and goals of your discipline and describe how these will inform your approach to TA work.

- $\quad$ List your teaching related experience and the associated skills that you bring to the teaching assistant role (for example, from being a swimming instructor or tutor).

- $\quad$ Recall successful teaching strategies that you encountered during your undergraduate degree and previous TA experience (if applicable).

Seek the following:

KNOWLEDGE of...

1. How to develop a personal teaching identity

Possible learning activities/goals/outcomes:

- Investigate teaching philosophy statements or revisit your own, so that you can think about the values and goals you deem important in a teaching role.

- Search out the rights and responsibilities associated with your TA role and reflect on your approach to fulfilling these duties.

- Seek feedback early, mid- and end-of term through a combination of observation and/or written responses by professionals, peers, and students, about your teaching, facilitating, or other duties performed.

- Be critically self-reflective about the strategies and methods you employ in your TA work in order to continually improve your ability to provide the best conditions for students' learning.

2. Discipline specific content knowledge related to the course assigned

Possible learning activities/goals/outcomes:

- $\quad$ Seek to be familiar with the content that is directly pertinent to the duties you will be performing.

3. Pedagogy and teaching strategies suitable to duties assigned

Possible learning activities/goals/outcomes:

- $\quad$ Find out the most appropriate pedagogical methods to successfully fulfill those duties. For example, if you have been assigned to lead discussion in tutorials, seek out strategies that you can use to encourage discussion, how to develop questions suitable for the content, and how to work with students of differing abilities and engagement. Through professional development opportunities, you will seek out knowledge about pedagogy and teaching strategies to enhance your TA work.

4. What is meant by learning-centeredness

Possible learning activities/goals/outcomes:

- Understand that your work is about the learner and find information about ways to accommodate the learning needs of students.

SKILLS about..

1. What is required to perform duties assigned

Possible learning activities/goals/outcomes:

- Learn the skills required to fulfill those duties. These skills may include, but are not limited to: learning how to prepare lesson plans, rubrics, class outlines, or student feedback forms; use classroom and online technology; work with a diverse student population; give clear, concise, and stimulating presentations; keep a focus on learner centered teaching; mentor students; actively listen; give and receive feedback; help students work effectively in groups; engage in effective communication; and ask effective questions.

2. How to navigate challenges

Possible learning activities/goals/outcomes:

- Manage your time efficiently, set priorities, manage the classroom, resolve conflict, and manage student expectations so that you do not encounter adverse challenges in your work.

ABILITY to..

1. Demonstrate professionalism

Possible learning activities/goals/outcomes:

- $\quad$ Aim to be professional, confident, sensitive, and resilient with your interactions with everyone you work with.

- $\quad$ Ensure that you maintain integrity and confidentiality of student work at all times.

- $\quad$ Actively balance your time between work and life, and plan future goals.

- $\quad$ Develop lifelong learning habits and engage in reflective practice about your work and teaching.

2. Develop strategies for effective interpersonal communication

Possible learning activities/goals/outcomes:

- Actively seek answers from the course supervisor through appropriate communication channels about the questions you have about your TA role, while establishing and maintaining a professional relationship.

- With colleagues, you will seek out support, resources, and engage in a collegial collaborative relationship by participating in professional development provided by your department and other units on campus.

- With students, you will be available, approachable, inclusive, fair, and enthusiastic in all communication while maintaining professional boundaries.

\section{Figure 3}

Framework for teaching assistant competency development (text) 
At the beginning of the workshop, participants (about 25 that work specifically with graduate student professional development programming) were first asked whether TAGSA should continue refining the competencies, move to testing them, or dismiss the whole idea. The group was also asked if there were other ideas or approaches that TAGSA should consider. There was consensus that TAGSA should continue the work on the TA competencies. At that point, participants were asked to work in groups with the pared down visual representation to discuss what could be done next and to consider how they could test a part of the framework or the entire framework at their institution (no guidelines were provided but left to each person to approach development in the way that best suited his or her institution). The group at STLHE 2014 appreciated the visual conceptualization but argued that more context was required. After significant discussion, it was decided to keep the visual representation but include the competency details that were developed and presented at EDC 2014.

\section{Moving forward}

TAGSA's primary goal for the TA competency development project has been to ensure that the framework is broadly implemented. After STLHE 2014, the completed document incorporated the key aspects that were consistent throughout the collaborative process. It is broad but directed, and flexible and adaptable enough so that it can be used by multiple institutions and groups within institutions.

This final framework was distributed through appropriate listservs (EDC, POD, STLHE, and TAGSA) so that educational developers, faculty, TA program coordinators, and anyone else interested could use the framework over the 2014/2015 academic year. We asked the TAGSA pre-conference group to consider adopting part of or the entire framework and to report back at the TAGSA preconference of STLHE 2015. Specifically, we are interested in knowing: what was done, what worked, what changes may be necessary, and the successes and challenges experienced. The TAGSA pre-conference will include a session devoted to discussion about these pilot implementations. Our intent is that through piloting the competency framework in different ways, we will have a good sense of how to develop supplementary materials to encourage broad adoption and use of the competencies to assist faculty, departments, educational developers, and TA program coordinators. We look forward to sharing results and furthering development of these national TA competencies to help ensure that TAs are supported in the academic workplace.

\section{References}

Association of Universities and Colleges of Canada. (2011). Trends in higher education: Volume 1 - Enrolment. AUCC: Ottawa, ON. http://www.univcan.ca/wp-content/uploads /2011/05/trends-2011-vol1-enrolment-e.pd $\mathrm{f}$

Bloom, B. S. (Ed.). (1956). Taxonomy of education objectives: The classification of educational goals. New York: Longman.

Dreyfus, S. E., \& Dreyfus, H. L. (1980). A five-stage model of the mental activities involved in directed skill acquisition. University of California, Berkeley.

Korpan, C. (2012). Teaching assistant competencies: A Canadian perspective. Paper prepared for the Educational Developers Caucus, WilfredLaurier University, Ontario, Canada.

Maldonado, V., Wiggers, R., \& Arnold, C. (2013). So you want to earn a PhD? The attraction, realities, and outcomes of pursuing a doctorate. Toronto: Higher Education Quality Council of Ontario. http://www.heqco.ca/SiteColl ectionDocuments/At\%20Issue\%20Doctoral \%20ENGLISH.pdf 
McAlpine, L., \& Åkerlind, G.S. (Eds.). (2010). Becoming an academic: International perspectives. Basingstoke, Hampshire: Palgrave Macmillan.

Roehrig, G., Luft, J., Kurdziel, J., \& Turner, J. (2003). Graduate teaching assistants and inquiry-based instruction: Implications for graduate teaching assistant training. Journal of Chemical Education, 80, 1206-1210. http://dx.doi.org/10.1021/ed080p1206

Rose, M. (2012). Graduate student professional development: A survey with recommendations. Unpublished report. Brock University. http://www.cags.ca/documents/publications /working/Report\%20on\%20Graduate\%20S tudent $\% 20$ Professional\%20Development $\%$ 20\%20-\%20A\%20survey\%20with\%20reco mmendations $\% 20$ FINAL $\% 20$ Eng.OCT\%2 02012.pdf

Schönwetter, D. J., \& Ellis, D. (2007). Sharing competency commonalities and uniqueness across Canadian TA programs. Paper presented at the Educational Developers Caucus, University of Guelph, Ontario, Canada.

Simpson, R. D., \& Smith, K. S. (1993). Validating teaching competencies for graduate teaching assistants: A national study using the Delphi method. Innovative Higher Education, 18, 133-146. http://dx.doi.org/10.1007/BF011 91891

Smith, M. K. (1996, 2005). Competence and competencies. The Encyclopedia of Informal Education. Retrieved from http://www.infed.org/biblio/b-comp.htm

Society for Teaching and Learning in Higher Education. (1996). Ethical Principles in University Teaching. Retrieved from http://www.stlhe.ca/awards/3m-national-tea ching-fellowships/initiatives/ethical-principl es-in-university-teaching/

Weinert, F. E. (2001): Competencies and key competencies: Educational perspective. In N. J. Smelser and P. B. Baltes (Eds.), International Encyclopedia of the Social and Behavioral Sciences, 4, 2433-2436.

\section{Acknowledgement}

The framework for teaching assistant (TA) competency development was developed by the Teaching Assistant Graduate Student Advancement (TAGSA) SIG of the Society of Teaching and Learning in Higher Education (STLHE). The authors would like to thank all colleagues who have contributed to the development of the TA competencies. Your valuable input has made the process especially rewarding and we look forward to further conversations and iterations.

\section{Biographies}

Cynthia Korpan is the Professional Development Programs and TA Training Manager at the Learning and Teaching Centre at the University of Victoria. Concurrently, Cynthia is a PhD Interdisciplinary candidate, and in her second term as chair of Teaching Assistant and Graduate Student Advancement (TAGSA) special interest group of the Society for Teaching and Learning in Higher Education.

Dr. Suzanne Le-May Sheffield is the Director of the Centre for Learning and Teaching at Dalhousie University. She administers the Certificate in University Teaching and Learning for graduate students and teaches the graduate course that is part of the Certificate. She has long been interested in the development of graduate students as teachers. 
Roselynn Verwoord is a $\mathrm{PhD}$ Student in the Department of Educational Studies at the University of British Columbia (UBC) and a Curriculum Consultant at the UBC Centre for Teaching Learning and Technology. Her academic interests include SoTL, curriculum development, graduate student development, and teacher education. 